\title{
Effects of Teaching through Online Teacher versus Real Teacher on Student Learning in the Classroom
}

\author{
Sirous Hadadnia \\ Islamic Azad University-Mamasani Branch, Iran \\ Norouz Hadadnia \\ Zargan Office of Education, Iran \\ Nina Shahidi \\ Islamic Azad University-Mamasani Branch, Iran
}

\begin{abstract}
This study was conducted with the purpose of comparing the effect of teaching of the online teacher with that of the real teacher on the students' learning in the university classroom. The study was conducted in the academic year 2009-2010. The sample of the study consisted of 80 students working either in control group or experimental group, 40 in each. The subjects were chosen and assigned by cluster sampling method. For data gathering, a 40 item test was administered in given time intervals to measure prior knowledge, achievement and retention of learning. Research methodology is of empirical, applied, and prospective nature. For data analysis, a t-test for comparing the differences between mean scores was employed. Based on the findings of this study, it appears that to overcome the lack of skilled university instructors, one could use online teachers. The quality of learning provided by the online teacher is the same as the one provided by the real teacher. In the university classrooms, one can use online teachers instead of the real teacher for a number of reasons. Finally, the degree of learning retention in both types of instruction (online versus traditional) is the same.
\end{abstract}

Keywords: Online learning; Virtual teaching; Face-to-face instruction; Online teacher; Distance education

\section{Introduction}

Education through virtual instructor is a type of teaching and learning in which the teachers and learners are geographically separated from each other. Therefore, to provide educational services, one needs electronic means such as texts, computer and internet to provide them. Due to a number of reasons, including some fields of study being new in Iran or the complexity of some other fields, supply of skilled and experienced instructors for universities in remote areas is difficult or impossible in some cases. Thus, either those fields of study and courses are not offered or are taught using teachers with secondary specialties. In any case, they lead to academic damages in universities (Sarmadi, 2005).

Mehrpouya (2004) classifies virtual education in two groups. The first type is intra-school programs. In these programs the learners learn through the internet at their place of study in groups supervised by the officials. The second type is extra-school programs which are more 
common in reality. In these programs, the individuals learn at their own homes or even at their workplaces individually by connecting to internet. UNESCO states that intra-school distance learning programs are used to support education at schools where there is no learning materials available. They could also be used where the teachers have not formal abilities or to support schools where the number of learners is too low to implement traditional education.

According to Nichols (2003) virtual education could be used in many ways and to teach the learners in one of the two forms: synchronously and asynchronously. Through this education, the information of the learners may be updated. Also, in cases where the learners have problems, they can communicate with their teachers. Finally, he reports different views and opinions of the virtual education authorities.

Baras (2000) believes that the increasing development of science and technology of today entails new methods of teaching and learning. The use of the theory of "the teacher, the only knowledgeable on the scene" is already an old and rejected belief. Learners must play a more active role in teaching and learning, and the teacher must turn into the guide by the side, the facilitator, the mediator and the education designer. However, the realization of all these responsibilities and functions in a physical classroom with fixed area, a given time, and traditional educational approach is difficult. Live education based on the classroom have high costs for their executors, while in online learning the persons are able to learn the information they are required any time of the day and any day of the week. In e-learning, the costs of movement (or transportation) and wasting of time is avoided. Therefore, examination of the possibility for establishment of such education and studying its efficiency and effectiveness seems necessary.

Keegan (2000) lists features of online education as follows: freedom from the constraint of scheduled classes, freedom from closed places, and freedom from time constraints.

Mehrmohammadi (2002) states that learning is not limited to what you learn in the classroom. Enjoying the technology for the purpose of development and growth of education will lead into the flooding of huge benefits for all layers of the society.

Yaghma (2009) indicates that the bases of educational technology (including online education), are rooted in the behaviorist psychological theory. In contemporary educational technology, boosting and deepening of knowledge, self- assessment and receiving feedback, retrieving the information required, carrying out laboratory and field work activities at virtual environments, generation of knowledge and provision of creativity, using electronic communication devices are sought.

Nowrouzi (2006), conducting a study with the aim of reviewing different methods of using IT in the learning process, arrived at the following conclusions: The appropriate method for application of IT in the learning process in the public course is utilizing self-learner multimedia software and simulations, whereas the methods based on internet are more appropriate for theoretical high school and technical high school courses.

Villegas-Reimers (2008) reported the following results: Using computers for education has found more representation in educational contents and course learning and has been stated as an alternative to the classical view, the purpose of which is providing learning in individual form instead of in group form. Based on this, internet has provided many basic alternative solutions and means which are capable to replace the classical education systems. This means 
having a significant advantage in the distance learning system and this way the real progress in completion and even replacing the teachers has been made possible by extensive facilities for storing information in large archive files.

Vilhem (2004) concluded that "the education trustees can, for improvement of the teachinglearning process, use different tools of IT in any conditions, including the computer, LAN, and internet, and this entails that they believe in the role of a guide by the side, not a wise at the scene".

Johnson, Hornik, and Salas (2007) suggested that of the factors that lead to limitation in successful implementation of e-learning, one can mention non-acceptation of e- learning by the user, insufficient fluency in working with computer by the user, and presence of stress while working with the e-learning environment in general and concluded that we must use the experiences that provide a common sense in the online classroom.

Wu et al. (2008) showed that comprehensive e-learning development using the hypercube model by studying basic differences and comparison of the natures of their technological elements (technology, content, infrastructure) with the present situation of e-learning and review of abilities of educational institutions shall be possible based on an outlook for implementation and effective and innovative management of e-learning

Adibi (2010) believes that online education gives the learner the ability to learn anywhere, anytime and even it pays attention to the pace of learning for each individual; that is, learning with high flexibility, and mentions the fact that in this type of education, the learner is himself a decision-maker and can debate or speak with teachers and students using ICT.

George (2009) elaborates the use of the six efficient words of "what, which, why, where, when and who" in the initial implementation of e-learning and believes that providing education in electronic form is providing opportunities for the students in potential use of technology to improve teaching and learning. Therefore, all aspects must be studied for its establishment.

Etienne and van den Stock (2010) show that the main points of success for continuation of elearning are free access to the tools, high interest and motivation of teachers, the situation of learning based approach, structure development, visual processes of decision - making and the culture of using that education.

Stricker, Weibel, and Wissmath (2011) state that an approach to the cognitive power, computer learnt-outs, mediation, learning style, access to infrastructure, and the gender distribution are useful to a relatively high degree in successful implementation of online education; self-regulated learning is realized through an appropriate educational environment. A significant relationship between the student's motivation and effort was seen in this environment and at last suitable use of learning resources as a part of supervised aptitude was considered.

Considering all these views and debates, now the question is: Regarding the quality of learning, is there a difference between education through an online teacher and a real teacher? Within the context of the universities in a country enjoying high-tech computer science, especially high-speed internet lines, could online teachers be used instead of real teachers in real university classrooms? In other words, could online teachers be used to remove the paucity of skilled teachers in universities? These questions frame the problem of the present study. Due 
to the necessity of this kind of research and importance of the subject for countries such as Iran, the current study was conducted to answers to these questions.

\section{Purpose}

The main purpose of this study is comparing the effects of teaching through online teachers versus the real teachers on student learning in the actual university classroom. Sub-purposes of the study are:

1. To study the possibility for establishment of real classrooms using online teachers with optimal quality in learning

2. To compare the overall quality of learning through teaching with online teacher and teacher in person

3. To study the possibility of using online teachers instead of real teachers

4. To compare the level of retention in learning through online education versus faceto-face education

To find statistically reliable answers to the above questions, the following hypotheses were formed and tested in this study. Each of these hypotheses is directly connected with each of the questions raised.

1. One can use online teachers to overcome the lack of skilled teachers in universities

2. The quality of learning through an online teacher is the same as that of a real teacher

3. One can use online teachers instead of real teachers in educational environments

4. The level of retention in learning is the same for online and face-to-face instruction

\section{Methodology}

Since the focus of this study is achievement of a practical outcome concerning the creation of a special type of education called "centralized online education", it is an applied research. The study is also experimental because a random method has been used to choose the subjects and the treatments were conducted by paying particular attention to the control of variables in an experimental environment. Since the findings of the study are obtained by modification of variables with some implications for the future, it is also a prospective research. Therefore, it is generally an experimental, applied, and prospective study.

The methodological procedures were conducted as follows: After placing the groups in two separate classrooms, a teacher-made test consisting of 40 questions with a total score of 20 was given as the pre-test. Then, concurrently the control group classroom was subject to teaching by the traditional face-to-face method; while the experimental group in the other classroom was subject to online instruction. Following the implementation of treatments, using the teacher-developed achievement measure consisting of 40 items, the posttest was administered on both groups. 
After elapse of two weeks, again the teacher-made learning retention test with 40 items was conducted and the findings were statistically analyzed. In this study, a research design of the real experiment of the pre-test and post-test design with the control group was used; therefore, the level of learning in the control group and the experimental group both before and after the introduction of the independent variable was compared to determine the effect of the independent variable on learning.

The pre-test, post-test design with the control group

$\begin{array}{cccc}R E & T 1 & * & T 2 \\ R C & T 1 & - & T 2\end{array}$

\section{The Sample}

The population of this study consisted of all students of Islamic Azad University-Marvdasht Branch, where there were 13,158 students in the academic year of 2009-2010. From this population, 80 students were selected as the sample of the study.

In order to estimate the required sample size, prior studies of the similar nature and research methodology books were examined. Based on the relevant literature requiring a minimum of 15 subjects in each cell of an experimental study, the number of subjects in the control group and the experimental group were determined to be 40 students each.

The sampling method was cluster assignment because four existing groups (each including 20 students) from different courses and fields of study were assigned to control and experimental groups without random selection of individuals.

\section{Data Gathering Instrument}

As mentioned earlier, the instrument for collection of data in this study consisted of 3 tests, each covering 40 questions with 4 choices. These tests were developed by the researcher in close collaboration with prominent university instructors and implemented in three stages. Since the author has developed this test by carefully studying different books on educational measurement and evaluation and because it was reviewed and approved by authorities in the subject matter area after its development, it was assumed to be valid. To calculate reliability of the tests, Cronbach's alpha reliability coefficient was used. Based on three applications for pretest, post-test, and retention test, the alpha coefficient was found to be $0.87,0.85$, and 0.81 , respectively.

\section{Methods for the Analysis of Data}

Both descriptive and inferential statistics were used in the study. With regard to descriptive statistics, mean scores as a central tendency measure and standard deviations as a measure of variability were calculated. Then, the individual score differences between pre-test and posttest performance of each subject was computed, producing gain scores. Following this, the 
overall mean scores for both the control group and the experimental group were calculated. Regarding the inferential statistics, the t-test for comparison of mean scores for independent groups was conducted.

\section{Findings}

The findings of the study were reported in conjunction with the hypotheses mentioned earlier under the title of purpose. Following relevant tables, the interpretations of the findings were presented under each hypothesis.

The first hypothesis: One can use online teachers to overcome the lack of skilled instructors in universities

To test this hypothesis, the t-test for independent groups was used. Obtained t-value is 32.88 , which is significant at 0.0001 level with 78 degrees of freedom (df). Because the calculated significance level is less than 0.05 , and considering the fact that the mean score of the experimental group is higher than the mean score of the control group, the first hypothesis was approved (Table 1).

Table 1. The t-test for Comparison of the Means of Scores of the Experimental and the Control Group in the First Hypothesis

\begin{tabular}{l|c|c|c|c|c|c}
\hline \hline Group & $\mathrm{n}$ & Mean & $\mathrm{SD}$ & $\mathrm{t}$ & $\mathrm{df}$ & Significance level \\
\hline \hline Experimental & 40 & 13.5 & 2.85 & \multirow{2}{*}{32.88} & 78 & 0.0001 \\
\cline { 1 - 5 } Control & 40 & 6.95 & 3.75 & & & \\
\hline \hline
\end{tabular}

The second hypothesis: The quality of learning through an online teacher is the same as that of a real teacher

In the study of testing the second hypothesis, the obtained t-value is seen to be 9.26 , which is statistically significant at 0.0001 level with $78 \mathrm{df}$. Because the calculated significance level is less than the assumed level of significance as 0.05 , and this difference is due to superior mean score of the experimental group relative to the mean score of the control group, this finding is interpreted as refusal of the hypothesis that claim no difference between means, which is in favor of online learning (Table 2).

Table 2. The t- test for Comparison of the Means of the Experimental and the Control Group about the Second Hypothesis

\begin{tabular}{l|c|c|c|c|c|c}
\hline \hline Group & $\mathrm{n}$ & Mean & SD & $\mathrm{t}$ & $\mathrm{df}$ & Significance level \\
\hline \hline Experimental & 40 & 6.55 & 1.25 & 9.26 & 78 & 0.0001 \\
\cline { 1 - 4 } Control & 40 & 4.2 & 0.99 & & & \\
\hline \hline
\end{tabular}




\section{The third hypothesis: One can use online teachers instead of real teachers in educational environments}

To test this hypothesis, the t-test of independent groups was used. Obtained t-value is 24.77 , which is significant at 0.0001 level with $78 \mathrm{df}$. Because the calculated significance level is less than 0.05 , and in view of the fact that the mean score of the experimental group is higher than that of the control group, the third hypothesis is supported (Table 3). Note that this hypothesis is directional and the finding is in favor of online learning.

Table 3. The t-test for Comparison of the Mean Scores of the Experimental and the Control Group for the Third Hypothesis

\begin{tabular}{l|c|c|c|c|c|c}
\hline \hline Group & $\mathrm{n}$ & Mean & $\mathrm{SD}$ & $\mathrm{t}$ & $\mathrm{df}$ & Significance level \\
\hline \hline Experimental & 40 & 11.7 & 2.57 & 24.77 & 78 & 0.0001 \\
\cline { 1 - 5 } Control & 40 & 5.62 & 3.21 & & & \\
\hline \hline
\end{tabular}

The fourth hypothesis: The level of retention in learning is the same for online and face-toface instruction

By testing this hypothesis we see that the obtained t-value is 1.04 , which produced a $p=0.29$ with $78 \mathrm{df}$. Because the acceptable significance level is $p=0.05$ and the obtained $p$ value is greater than the critical alpha level, we conclude that there is no significant difference in terms of retention in learning of students under both methods so that the fourth hypothesis is supported (Table 4).

Table 4. The t-test for Comparison of the Mean Scores of the Experimental and the Control Groups for the Fourth Hypothesis

\begin{tabular}{l|c|c|c|c|c|c}
\hline \hline Group & $\mathrm{n}$ & Mean & $\mathrm{SD}$ & $\mathrm{t}$ & $\mathrm{df}$ & Significance level \\
\hline \hline Experimental & 40 & 02 & 0.81 & 1.04 & 78 & 0.29 \\
\cline { 1 - 5 } Control & 40 & 02.52 & 2.06 & & & \\
\hline \hline
\end{tabular}

\section{Discussion and Conclusion}

This study was conducted with the main purpose of comparing the effect of teaching by online teacher versus real teacher on the learning of students in real classrooms at the university level. Subjects in the control group were taught through traditional face-to-face instruction, whereas subjects in the experimental group were taught through online instructor. A multiple choice pre-test, post-test, and retention test were administered to measure prior knowledge, learning gains, and retention of students

Based on the findings of the study, one can conclude that it is possible to use online teachers to overcome the lack of expert instructors in universities. This is consistent with the view of Baras (2000) who believes that the increasing growth of science and technology today entails new teaching and learning methods supporting the idea that learners must play more active roles in the teaching and learning process, while the teacher must turn into a leading guide, a facilitator, a mediator, and an educational designer. Of course, realization of these functions in 
a physical classroom is difficult for many reasons including but not limited to insufficient physical space, time constraints, lack of technology, and traditional approaches to education. Live education in the classroom also have high costs for their executors, while in online learning the persons are able to learn the information they are required any time of the day and any day of the week with relatively low cost and open access materials. This certainly offers support to Adibi's stand (2009), which showed that online learning is possible with high speed in learning anytime and anywhere.

For the second hypothesis, we concluded that the quality of student learning as an outcome of teaching through online instructors is the same as the outcome of teaching through real teachers. Vilhem (2003) reported similar findings suggesting that most students have a positive experience from online classes and they generally stated that in online classes, just like the common traditional ones, learning was highly desirable. This finding, too, is in accordance with the findings of George (2009), who believes that provision of education in electronic form is providing opportunities for students in potential use of technology for upgrading teaching and learning. Based on the large body of literature in the field of educational technology in general and in the area of electronic learning, this comes as no surprise because online technologies provide more flexibility and freedom for students.

The third hypothesis of the study had indicated that one can successfully use an online teacher instead of a real teacher in educational environments. The findings of the study offer support for this idea. We can safely conclude that online learning has at least no harm on student performance and attitudes. Nafissi (2004) in a similar study found the supporting evidence in line of this result and then stated that "the education trustees can, for improvement of the teaching- learning process, use different tools of IT in any conditions including the computer, LAN, and internet, and this entails that they believe in the role of "a guide by the side, not a wise at the scene".

The fourth hypothesis claimed that retention of learning as an outcome of online instruction is the same as that of the traditional face-to-face instruction. The results of the study showed no significant difference, thus it offers support for more use of online teaching under certain conditions. However, one should keep in mind that more doesn't always mean better so that online educators should pay attention to principles of effective instruction regardless of the technology. This results generally supports the view of Yaghma (2009) stating that educational technology supports boosting and deepening of the prior learning, self- assessment and receiving feedback, retrieving the information required, carrying out laboratory and field work activities at virtual environments, generation of knowledge and provision of creativity, using electronic devices as well as communication tools.

\section{Recommendations}

Based on the findings of the present study, the following recommendations can be made for possible improvements in university education through online learning:

1. Due to the success of online teaching, all universities and educational centers should be equipped with the facilities required for this type of instruction.

2. Considering the lack of skilled instructors who can teach in the classroom at least in some fields of study, online teachers can be used as a solution. 
3. Particularly through asynchronous online teaching, different groups of the same course can concurrently benefit from the same instructor.

4. For serious reduction in transportation costs and waste of time, the online instructor can teach several courses at the same time in several places.

\section{References}

Adibi, M. (2010). The effect of information and communication technology on the educational improvement of secondary students (Unpublished master's thesis). Islamic Azad University-Garmsar Branch.

Baras, J. S. (2000). Educational connoisseurship and critics. Journal of General Education, 4(2), 213-245.

Etienne, P. \& van den Stock, A. (2010). E-learning-assistant: Situation-based learning in education. Computer and Education Journal, 39(3), 224-226.

George J. (2009). Social grid platform for collaborative online learning on blogosphere: A case study of eLearning. Expert Systems with Applications, 36, 2177-2186.

Johnson, R ., Hornik, S., \& Salas, E. (2007). An empirical examination of factors contributing to the creation of successful e-learning environments. International Journal of HumanComputer Studies, 66(5), 356-369.

Keegan, D. (Ed.). (1993). Theoretical principles of distance education. London: Routledge.

Mehrmohammadi , M. (2002, July). Online education. Proceedings of the third conference of quality managers (131-153). Tehran: Iranian Standard and Industrial Research Organization. Available online at: www.qmconference.com/indexFa.aspx?p=25

Mehrpouya , A. (2004). Online universities and the appropriate model for higher education system. Tehran: Andishe.

Nafissi, M. (2004). Strategies for ICT development. Tehran: Danesh.

Nichols, M. (2003). A theory for e-learning. Journal of Educational Technology \& Society, 6 (2). Available online: http://www.ifets.info/journals/6_2/1.html

Nowrouzi , M. (2006), Learning toward dynamic and creative education. Proceedings of the second symposium of the place of norms in the primary education (pp.21-23). Tehran: Terabit.

Sarmadi, M. (2005). On practical strategies for using distance learning. Quarterly Journal of Technology Leadership \& Administration, 1, 12-16.

Stricker, D., Weibel, D., \& Wissmath, B. (2011). Efficient learning using a virtual learning environment in a university class. Computers \& Education, 56(2), 495-504.

Vilhem, W. J. (2004). Educational evaluation. Catholic Higher Education Journal, 11(3), 61-62.

Villegas-Reimers, E. (2008). Teacher professional development: An international review of literature. Paris: UNESCO.

Wu , J., Tennyson , R., Hsia, T., \& Liao, Y. (2008). Analysis of e-learning innovation and core capability using a hypercube model. Computers in Human Behavior, 24(5), 1851-1866.

Yaghma, A. (2009). Learning aid devices. Tehran: Madreseh. 
Correspondence: Sirous Hadadnia, Faculty Member and the Group Manager of the School of Educational Science, Islamic Azad University-Mamasani Branch, Shiraz, Iran 